\title{
Selection of Supply Chain Partners for Small and Medium-Sized Manufacturing Enterprises
}

\author{
Tongjuan Liu ${ }^{1, a}$,Lanqing Yang ${ }^{2, b^{*}}$ \\ ${ }^{1}$ Beijing WUZI University, China \\ ${ }^{2}$ Beijing WUZI University, China \\ altj7905@163.com, ${ }^{\text {b532629916@qq.com }}$
}

\begin{abstract}
Keywords:Selection of Cooperation Partner. Supply Chain. Analytic Network Process. Data Envelopment Analysis
\end{abstract}

Abstract : Supply Chain Partnership means a strategic relationship which is reached a long-term cooperation agreement between upstream and downstream entities in the same supply chain. Establishing a good supply chain partnership help to reduce the cost, shorten the reaction time and create the new market value and so on, and to successfully build supply chain strategic partnership, one of the key aspects is to choose partners. Through analyzing the problem that is selecting the small and medium-sized manufacturing enterprises partners (upstream parts suppliers), the full text will establish a reliable supplier evaluation system and a mathematical model using the analytic network process (ANP) / data envelopment analysis (DEA) method, and will derived the basic theory and methods adapted to the small and medium-sized manufacturing enterprises partners selection to help companies better implement supply chain management.

\section{Introduction}

In today's competitive international environment, competition between enterprises has transformed the competition between supply chains. The traditional view is that choosing the right partner is mainly to reduce procurement costs, so as to achieve the purpose of reducing expenses. But now the choice of partners was transformed into a strategic activity, choosing the right partner is to establish stable relations of cooperation, so as to stabilize the entire supply chain. It is becoming the problem had to think is that manufacturing companies how to make itself as the core, to build the enterprise supply chain adapted itself and to choose its enterprise partners. Based on this, this paper puts forward the supply chain partner selection model, and accordingly raise the new supply chain partner selection method - based on two-stage supply chain partners selection method of data envelopment analysis and network analysis, and provides reference for the implementation of supply chain management integration and the reasonable choice of supply chain partners.

\section{DEA Supplier Selection Efficiency Evaluation System}

\section{A. Identify Indicators}

This paper selects some of indicators which are more readily available and relatively stable, and take the smaller, the better indicators as input variables and the bigger, the better indicator as output variables.

1. Input Indicators: This article will input four indicators: price, the level of on time delivery, the average rate of customer complaints, after-sales service, these indicators are the small, the better indicators and easier available.

1) Price $X_{1}$ : indicates weighted average price which is used by batch and weight given by shipments, $\mathrm{P}$ represents the weighted average price, $W_{\mathrm{i}}$ is the price when the number of the supply goods is $X_{i}$, and the formula is expressed as follow: $P=\sum_{i=1}^{n} W_{i} X_{i} / \sum_{i=1}^{n} W_{i}$

2) The Level of On-Time Delivery: It means the enterprise in accordance with the requirements of the goods delivered on time, inputting on the basis of the late number of the supply goods. 
3) The Average Rate of Customer Complaints: The average rate of customer complaints= (the number of enterprises given negative evaluation/ cooperation with the vendor of business partner confession) $\times 100 \%$

4) After-Sales Service: the respond days of suppliers received service requests $\times$ the average number of items rework

2. Output Indicators: In this paper, these output indicators will be act as three indicators: quality level, the emergency supply capacity and supply history, these indicators are the bigger, the better for suppliers when they were quantified.

1) The Level of Quality $Y_{1}$ : It means the number of the qualified product of the arrival products.

2) The Emergency Supply Ability $Y_{2}$ : This indicator is that suppliers can provide the number of qualified products in a unit of time, and the number can be quantified by the enterprise temporary ordered expected-time and the on-time delivery. This indicator reflects the comprehensive inspect of suppliers' production and supply capacity, storage capacity, mobility capacity, coordination of action and other capabilities. In a dynamic market environment, it also is reflect the ability of suppliers in response to the changing economic situation and the performance of the supply chain agility, and it can also test supplies' ability of emergency response when the economic situation changes.

3) Supply history: By Availability to reflect the history of the total shipments. Trading success is the vendor's products in all respects to meet the business requirements, and the entire process is satisfactory to both sides.

\section{B. Based on the DEA Model to Construct $C^{2} R$ Model Supplier Efficiency Assessment}

1. The Model Process: Suppose there are W suppliers to efficiency assessment, each vendor has a input terms and $\mathrm{b}$ output terms (in this article $\mathrm{a}=4, \mathrm{~b}=3$ ), DM $U_{k}$ is the $\mathrm{k}$ supplier in $\mathrm{W}$ suppliers, a terms referred to as an input credited to: $X_{i}^{k}(\mathrm{i}=1,2,3,4)$, b output terms credited to: $Y_{j}^{k}(\mathrm{j}=1,2,3)$.Efficiency evaluation is the ratio of total output to the total input. DEA mathematical programming model is based on the goal of maximize the efficiency $E_{k}$ of the decision-making unit $\mathrm{DM} U_{k}$, finding the most favorable weight combination for the right $\mathrm{DM} U_{k}$ of inputs and outputs, and forcibly the total investment set to 1 for the sake of calculating easier, converting the general linear programming model then the formula CR mode is: $\max h_{k}=\sum_{j=1}^{b} u_{j}^{k} Y_{j}^{k}$

$$
\text { s.t }\left\{\begin{array}{l}
\sum_{i=1}^{a} v_{i}^{k} X_{i}^{k}=1 \\
\sum_{j=1}^{b} u_{j}^{k} Y_{j}^{r}-\sum_{i=1}^{a} v_{i}^{k} X_{i}^{r} \leq 0, r=1,2 \ldots W \\
v_{i}^{k} \geq \varepsilon>0, \mathrm{i}=1,2,3,4 \\
\mathrm{u}_{\mathrm{j}}^{\mathrm{k}} \geq \varepsilon>0, \mathrm{j}=1,2,3
\end{array}\right.
$$

(Among them $X_{i}^{r}, Y_{j}^{r}$ are the actual input-output data and the unknown variable weights are $u_{j}^{k}, v_{i}^{k}$, it is not a given but a calculated, and it is the favorable weight of investment and production under the target of maximize the efficiency.)

In order to facilitate the validation of DEA, according to the linear programming duality theory, introducing slack variables $S^{+}, S^{-}$and the non-Archimedes infinitesimal $\varepsilon$, and $\theta$ means efficiency value for the vendor $\mathrm{DM} U_{k}$, the greater $\theta$ means the higher efficiency of the $\mathrm{j}$ decision making unit and the more rationalize to allocation of resources the state, the smaller $\theta$ means the lower the efficiency of the $\mathrm{j}$ decision making unit and its values range is $[0,1]$. 


$$
\begin{gathered}
\max h_{k}=\theta-\varepsilon\left(\sum_{\mathrm{i}=1}^{\mathrm{a}} \mathrm{S}_{\mathrm{i}}^{-}-\sum_{j=1}^{b} S_{j=1}^{+}\right) \\
\text {s.t }\left\{\begin{array}{l}
\sum_{i}^{w} \lambda_{r} Y_{i}^{r}-\theta X_{i}^{k}+S_{i}^{-}=0, i=1,2,3,4 \\
\sum_{r=1}^{w} \lambda_{r} Y_{j}^{r}-S_{j}^{+}=Y_{j}^{k}, j=1,2,3 \\
S_{i}^{-}, S_{j}^{+} \geq 0, i=1,2,3,4, j=1,2,3
\end{array}\right.
\end{gathered}
$$

2) Economic Meaning of $C^{2} R$ Model Analysis:

a) When $\theta^{*}=1$, and $S_{j}^{+^{*}}+S_{i}^{-*}=0$,it means $\operatorname{DM} U_{k}$ is DEA effective, and its efficient frontier surface formed is constant returns to scale, and $\mathrm{DM} U_{k}$ is effective scale and technology, good allocation of resources and no waste loss.

b) When $\theta^{*}=1, S_{j}^{+^{*}} \neq 0$ or $S_{i}^{-^{*}} \neq 0$, it represents $\mathrm{DM} U_{k}$ is weak DEA efficient, and this supplier is close to the best allocation of resources, and in the original output unchanging, it can reduces some investment, or on the contrary.

c) When $\theta^{*}<1$, it is considered $\mathrm{DM} U_{k}$ is DEA invalid, invalid technical or invalid scale, and allocation of resources did not achieve the best state, so certain improvement should be made for the allocation of resources, such as changing the input to the original $\theta$ times.

\section{Based on ANP Evaluation System of Supply Chain Index}

\section{A. Determining the Indicators}

Based on principle of index system establishment and the guiding ideology, this paper had established four layer indicators, namely business performance evaluation, business capability evaluation, the cooperation between enterprises ability evaluation and enterprise environments; 5 second indicators, namely quality, cost, responsiveness, enterprise cooperation ability, communication ability. As a control layer, assuming that they are independent of each other, and the 16 index layer below the second layer indexes is non-independent (between certain factors are relevant) and we call it the network layer in Table I.

Table I

\begin{tabular}{|c|c|c|c|c|c|c|}
\hline $\begin{array}{l}\text { The target } \\
\text { layer }\end{array}$ & Rule layer & & Index layer & $\begin{array}{c}\text { Indicator } \\
\text { quantitative } \\
\text { values }\end{array}$ & $\begin{array}{l}\text { The index } \\
\text { type }\end{array}$ & $\begin{array}{c}\text { Indicator } \\
\text { quantitative } \\
\text { methods }\end{array}$ \\
\hline \multirow{5}{*}{$\begin{array}{l}\text { The } \\
\text { evaluation } \\
\text { index } \\
\text { system of } \\
\text { supply } \\
\text { chain }\end{array}$} & \multirow{5}{*}{$\begin{array}{c}\text { The product } \\
\text { competition } \\
\text { evaluation } \\
\text { A1 }\end{array}$} & \multirow{2}{*}{ Quality B1 } & $\begin{array}{l}\text { The rate of } \\
\text { qualified } \\
\text { products } \mathrm{C} 1\end{array}$ & $\begin{array}{c}\text { Qualified } \\
\text { products } \\
\text { accounted for } \\
\text { the ratio of total } \\
\text { output products }\end{array}$ & Quantitative & $\begin{array}{l}\text { Formula } \\
\text { calculate }\end{array}$ \\
\hline & & & $\begin{array}{l}\text { Quality system } \\
\text { C2 }\end{array}$ & $\begin{array}{l}\text { The quality } \\
\text { system with the } \\
\text { consistency of } \\
\text { the enterprise } \\
\text { requirement }\end{array}$ & Qualitative & $\begin{array}{l}\text { Experts } \\
\text { assess }\end{array}$ \\
\hline & & \multirow[b]{2}{*}{ CostB2 } & Product price $\mathrm{C} 3$ & $\begin{array}{c}\text { Product unit } \\
\text { price (weighted) }\end{array}$ & Quantitative & $\begin{array}{l}\text { Formula } \\
\text { calculate }\end{array}$ \\
\hline & & & $\begin{array}{c}\text { The rate of cost } \\
\text { efficiencyC4 }\end{array}$ & $\begin{array}{l}\text { The ratio of } \\
\text { profit and loss } \\
\text { cost }\end{array}$ & Quantitative & $\begin{array}{l}\text { Formula } \\
\text { calculate }\end{array}$ \\
\hline & & $\begin{array}{c}\text { Responsiveness } \\
\text { B3 }\end{array}$ & $\begin{array}{l}\text { Product flexible } \\
\text { C5 }\end{array}$ & $\begin{array}{l}\text { On time delivery } \\
\text { number, total }\end{array}$ & Quantitative & $\begin{array}{l}\text { Formula } \\
\text { calculate }\end{array}$ \\
\hline
\end{tabular}

Quantitative values and quantitative methods of evaluation index 


\begin{tabular}{|c|c|c|c|c|c|}
\hline & & & $\begin{array}{c}\text { number of } \\
\text { delivery }\end{array}$ & & \\
\hline & & EmergencyC6 & $\begin{array}{c}\text { In a certain time } \\
\text { of delivery } \\
\text { ability }\end{array}$ & Quantitative & $\begin{array}{l}\text { Historical } \\
\text { data }\end{array}$ \\
\hline \multirow{4}{*}{$\begin{array}{l}\text { Business } \\
\text { ability } \\
\text { evaluation } \\
\text { A2 }\end{array}$} & \multirow[b]{2}{*}{$\begin{array}{c}\text { Financial } \\
\text { situation B4 }\end{array}$} & $\begin{array}{c}\text { The rate of } \\
\text { capital turnover } \\
\text { C7 }\end{array}$ & $\begin{array}{l}\text { The ratio of } \\
\text { sales income and } \\
\text { total assets }\end{array}$ & Quantitative & $\begin{array}{l}\text { Formula } \\
\text { calculate }\end{array}$ \\
\hline & & $\begin{array}{l}\text { The rate of profit } \\
\text { growth } \mathrm{C} 8\end{array}$ & $\begin{array}{l}\text { The ratio of the } \\
\text { profits and } \\
\text { profits last year } \\
\text { added value and } \\
\text { the profits last } \\
\text { year }\end{array}$ & Quantitative & $\begin{array}{l}\text { Historical } \\
\text { data }\end{array}$ \\
\hline & \multirow[t]{2}{*}{$\begin{array}{c}\text { Business } \\
\text { situation B5 }\end{array}$} & $\begin{array}{l}\text { The rate of on } \\
\text { time delivery C } 9\end{array}$ & $\begin{array}{l}\text { The ratio of on } \\
\text { time delivery } \\
\text { number and the } \\
\text { total number of } \\
\text { delivery }\end{array}$ & Quantitative & $\begin{array}{l}\text { Formula } \\
\text { calculate }\end{array}$ \\
\hline & & $\begin{array}{l}\text { The rate of order } \\
\text { completion } \mathrm{C} 10\end{array}$ & $\begin{array}{c}\text { Reflect product } \\
\text { orders }\end{array}$ & Quantitative & $\begin{array}{l}\text { Formula } \\
\text { calculate }\end{array}$ \\
\hline \multirow{4}{*}{$\begin{array}{c}\text { The } \\
\text { cooperation } \\
\text { between } \\
\text { enterprises } \\
\text { ability } \\
\text { evaluation } \\
\text { A3 }\end{array}$} & \multirow{2}{*}{$\begin{array}{l}\text { Enterprise } \\
\text { cooperation } \\
\text { compatible B6 }\end{array}$} & $\begin{array}{c}\text { The strategic } \\
\text { target } \\
\text { consistency C11 }\end{array}$ & $\begin{array}{c}\text { Goals are or not } \\
\text { consistent } \\
\text { between } \\
\text { enterprises } \\
\end{array}$ & Qualitative & $\begin{array}{l}\text { Experts } \\
\text { assess }\end{array}$ \\
\hline & & $\begin{array}{c}\text { Information } \\
\text { platform } \\
\text { compatibility } \\
\text { C12 } \\
\end{array}$ & $\begin{array}{c}\text { Between } \\
\text { information } \\
\text { system can be or } \\
\text { not compatible }\end{array}$ & Qualitative & $\begin{array}{l}\text { Experts } \\
\text { assess }\end{array}$ \\
\hline & \multirow{2}{*}{$\begin{array}{l}\text { Communication } \\
\text { ability B7 }\end{array}$} & $\begin{array}{l}\text { Communication } \\
\text { degree } \mathrm{C} 13\end{array}$ & $\begin{array}{c}\text { The degree of } \\
\text { communication } \\
\text { with the partners }\end{array}$ & Qualitative & $\begin{array}{l}\text { Experts } \\
\text { assess }\end{array}$ \\
\hline & & $\begin{array}{l}\text { Information level } \\
\text { C14 }\end{array}$ & $\begin{array}{c}\text { The degree of } \\
\text { information } \\
\text { sharing }\end{array}$ & Qualitative & $\begin{array}{l}\text { Experts } \\
\text { assess }\end{array}$ \\
\hline & \multirow[t]{2}{*}{$\begin{array}{c}\text { Evaluation } \\
\text { enterprise } \\
\text { environments B8 }\end{array}$} & $\begin{array}{l}\text { Public relations } \\
\text { C15 }\end{array}$ & $\begin{array}{l}\text { Relationship } \\
\text { with the media, } \\
\text { community, } \\
\text { government and } \\
\text { the public }\end{array}$ & Qualitative & $\begin{array}{l}\text { Experts } \\
\text { assess }\end{array}$ \\
\hline & & $\begin{array}{l}\text { The competitive } \\
\text { environment C16 }\end{array}$ & $\begin{array}{c}\text { The competitive } \\
\text { position in the } \\
\text { industry }\end{array}$ & Qualitative & $\begin{array}{l}\text { Experts } \\
\text { assess }\end{array}$ \\
\hline
\end{tabular}

\section{B. Based on ANP Supply Chain Evaluation Model Construction}

1. The main factor layer' weight matrix

Determining the element groups is determining the main factor layer' weight matrix, which is the degree of mutual influence structuring between the network layer element groups, that is to say, it is the relative importance of each element in the target group to $\mathrm{B}_{\mathrm{i}}(\mathrm{i}=1,2,3,4,5,6,7)$.If an element has no effect on the other elements in the ANP comparison matrix its value is 0 , that is different from the AHP, and the corresponding feature vector values is also 0 , the other are normalized.

\begin{tabular}{c|c|c}
$\mathrm{B}_{\mathrm{i}}$ & $\mathrm{B}_{1} \cdots \cdots \mathrm{B}_{\mathrm{n}}$ & $\begin{array}{c}\text { The normalized } \\
\text { feature veltor }\end{array}$ \\
\hline $\mathrm{B}_{1}$ & Comparison & $a_{1 i}$ \\
$\vdots$ & $\vdots$ \\
$\mathrm{B}_{\mathrm{n}}$ & matrix & $\vdots$ \\
$a_{n i}$
\end{tabular}

The last column normalized is gained by the algorithm based on the feature vector in AHP, all the normalized feature vector can composite matrix which is a weighted matrix $\mathrm{A}$ :( in that place $\mathrm{n}=$ 7, $\mathrm{A}$ is a non-negative matrix and its column sum is 1.) 
2. Secondary factor layer's super matrix

$$
\mathbf{A}=\left[\begin{array}{llll}
a_{11} & a_{12} & \mathrm{~L} & a_{1 n} \\
a_{21} & & \mathrm{~L} & a_{2 n} \\
\mathrm{M} & \mathrm{M} & \mathrm{L} & \mathrm{M} \\
a_{n 1 \mathrm{~K}} & a_{n 2} & \mathrm{~L} & a_{n n}
\end{array}\right]
$$

$\mathrm{Bi}$ is providing secondary factor $C_{i 1}, C_{i 2}, \ldots C_{i n i}, \mathrm{i}=1,2, \ldots \mathrm{n}$, the impact of elements $C_{j k}(\mathrm{k}=$ $1,2, \ldots, n_{i}$ ) of $B_{j}$ element set is gain by the pairwise comparison, constructing comparison matrix structure.

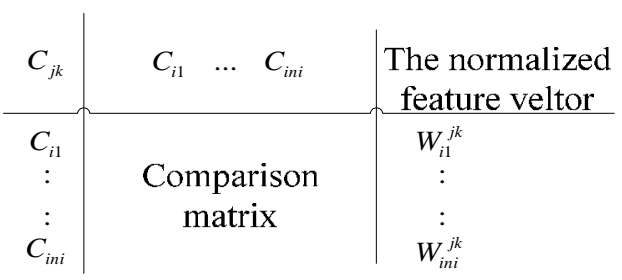

The relative influence of all elements in the $C_{i}$ to all elements in the $C_{j}$ in comparison matrix to calculate the normalized feature vector and make the matrix $W_{i j}$, as is shown in the below:

$$
W_{i j}=\left[\begin{array}{ccc}
W_{i 1}^{j 1} & \ldots & W_{\mathrm{i} 1}^{\mathrm{jni}} \\
W_{i 2}^{j 1} & \ldots & W_{i 2}^{j n i} \\
: & \cdots & : \\
: & \ldots & : \\
W_{i n i}^{j 1} & & W_{i n i}^{j l}
\end{array}\right]
$$

The column vector of $W_{i j}$ is the influence degree arrange elements of the $C_{i}$ elements to $C_{j}$ elements. If it is an element of $\mathrm{C}_{\mathrm{i}}$, then $W_{i j}=0$, and it can be obtained a super matrix in $\mathrm{B}_{\mathrm{i}}$ guidelines.

\section{Calculate the Weighted Super Matrix}

Weighted matrix constructs the mutual influence degree between the element group, and super matrix constructs the mutual influence degree between each element under element group, then the real impact relationship degree which is a dependent and feedback relationship of analysis network process (ANP) between elements can be represented through the weighted super matrix. Each element of the weighted matrix in step 1 multiply the blocks of super matrix in step 2 can constitute a weighted super matrix. Weighted super matrix reflects the control effect of the main factor to the second factor and the feedback effect of the second factor to the main factor, weighted super matrix $\bar{W}:=\bar{W} a_{i j} * W_{i j}$

\section{Solve the Index Weight}

The elements of super matrix $\bar{W}$ are $W_{\mathrm{ij}}$, then the size of $W_{i j}$ reflects the effect of element to element $\mathrm{j}$, and it also is the degree of dominance. The degree of dominance of element $\mathrm{i}$ to element $\mathrm{j}$ can be got by $\sum_{i=1}^{n} W_{i k} W_{k j}$, and it is the second degree of dominance. It is the element of $\bar{W}^{2}$ which is column normalization.

When $\bar{W}^{\infty}=\lim _{t-\infty} \overline{W^{t}}$ exists, the $\mathrm{j}$ column of $\bar{W}^{\infty}$ is the limits corresponding vector of each element in the network layer under the $B_{i}$ to the element $j$.

Because of the complexity of the ANP algorithm, this paper will adopt the SD (super decisions) decision making software to calculate this model. 


\section{A Company Partner Selection Evaluation Example}

This section will use the DEA and the ANP mathematical model aforementioned to solve the problem of selecting partners for an office equipment manufacturing limited company, and the supplier will be selected as the target evaluation assessment (as DMU), and be done specific calculations. As the company continues develop, the conflict between the $\mathrm{M}$ company and suppliers are increasingly fierce, and the suppliers are increasingly unable to meet the company's needs. Company executives believe that this issue must be put agenda, and the partners has become the biggest obstacle currently impeding the company forward.

Firstly, M company listed the deficiencies existing suppliers and the hope to build partnerships shown in Table II .

Table II

The deficiencies existing and hope to building partnerships

\begin{tabular}{c|c|c|c|c|c|c|c}
\hline & $\begin{array}{c}\text { The service } \\
\text { content }\end{array}$ & Stability & $\begin{array}{c}\text { The } \\
\text { market } \\
\text { reaction } \\
\text { speed }\end{array}$ & $\begin{array}{c}\text { Information } \\
\text { communication }\end{array}$ & $\begin{array}{c}\text { The } \\
\text { consistency } \\
\text { of quality }\end{array}$ & $\begin{array}{c}\text { The } \\
\text { timeliness } \\
\text { of delivery }\end{array}$ & $\begin{array}{c}\text { Number of } \\
\text { suppliers }\end{array}$ \\
\hline $\begin{array}{c}\text { Deficiencies } \\
\text { existing } \\
\text { suppliers }\end{array}$ & Product & $\begin{array}{c}\text { Frequent } \\
\text { changes }\end{array}$ & Slow & $\begin{array}{c}\text { Privileged } \\
\text { Information }\end{array}$ & Bad & Bad & Excellent \\
\hline $\begin{array}{c}\text { Hope to build } \\
\text { partnerships }\end{array}$ & $\begin{array}{c}\text { Products } \\
\text { and } \\
\text { strategic } \\
\text { cooperation }\end{array}$ & $\begin{array}{c}\text { Long-term } \\
\text { and close } \\
\text { cooperation }\end{array}$ & Fast & Information \\
sharing & $\begin{array}{c}\text { Fewer but } \\
\text { better }\end{array}$ \\
\hline
\end{tabular}

In summary, we can conclude that $\mathrm{M}$ company has been decided to re-select partners, because the relationship between the company and its partners were mainly "buy - sell" relationship. The major factor of selection partners is price, and if only one person to make a choice, it is inevitably existing empiricism, subjective judgment and personal factors doping, which will inevitably lead to more friction that appears in the process of cooperation partners with the company and can't reach an agreement in some important issues, such as data and information sharing, partners on product quality and response speed of assuring, which are directly bound by the M company's growth and development, and it also go against establish their own service characteristics on the opponent diverse markets .Next, this article will propose constructive solutions to solve the actual situation of the M company.

\section{A. Supplier Efficiency Evaluation \\ a. Original Data Processing}

Table III

A parts supply data

\begin{tabular}{c|c|c|c|c|c|c|c|c|c}
\hline $\begin{array}{c}\text { The } \\
\text { candidate } \\
\text { suppliers } \\
\text { number }\end{array}$ & $\begin{array}{c}\text { Price } \\
\text { level }\end{array}$ & $\begin{array}{c}\text { Quantity of } \\
\text { late } \\
\text { distribution } \\
(\mathrm{kg})\end{array}$ & $\begin{array}{c}\text { The } \\
\text { enterprise } \\
\text { of given } \\
\text { negative } \\
\text { evaluation }\end{array}$ & $\begin{array}{c}\text { The number } \\
\text { of } \\
\text { cooperative } \\
\text { enterprises }\end{array}$ & $\begin{array}{c}\text { Quant } \\
\text { ity of } \\
\text { return } \\
\mathrm{s}(\mathrm{kg})\end{array}$ & $\begin{array}{c}\text { Quantity } \\
\text { of } \\
\text { response } \\
\text { days }\end{array}$ & $\begin{array}{c}\text { The } \\
\text { level } \\
\text { quality }\end{array}$ & $\begin{array}{c}\text { The } \\
\text { emergency } \\
\text { supply } \\
\text { ability } \\
\text { (kg) }\end{array}$ & $\begin{array}{c}\text { Supply } \\
\text { history }\end{array}$ \\
\hline 1 & $\begin{array}{c}21.4 / 20 . \\
4 / 22.5 / 2 \\
1.9\end{array}$ & 3.0 & 2 & 33 & 6 & 2 & 40.3 & 590 & $\begin{array}{c}10.9 / 9.5 \\
79.6 / 11 . \\
5\end{array}$ \\
\hline 2 & $\begin{array}{c}19.6 / 21 . \\
3 / 21.9 / 2 \\
2.0\end{array}$ & 30.0 & 5 & 25 & 28 & 7 & 30 & 260 & $4.5 / 8.3 /$ \\
\hline 3 & $\begin{array}{c}22.7 / 22 . \\
5 / 23.7 / 2 \\
4.0\end{array}$ & 21.0 & 4 & 25 & 10 & 5 & & 290.10 .5 \\
\hline 4 & $\begin{array}{c}20.0 / 19 . \\
3 / 20.1 / 2 \\
1.4\end{array}$ & 6.0 & 1 & 50 & 8 & 1 & 25 & 550 & $\begin{array}{c}7.8 / 6.0 / \\
8.0 / 9.4\end{array}$ \\
\hline
\end{tabular}




\begin{tabular}{c|c|c|c|c|c|c|c|c|c}
\hline 5 & $\begin{array}{c}20.6 / 22 . \\
2 / 22.3 / 2 \\
3.1\end{array}$ & 7.0 & 1 & 20 & 19 & 1 & 30 & 400 & $\begin{array}{c}8.0 / 7.0 / \\
7.0 / 9.0\end{array}$ \\
\hline \multirow{2}{*}{6} & $\begin{array}{c}19.9 / 20 . \\
1 / 21.6 / 2 \\
3.5\end{array}$ & 48.0 & 2 & 20 & 17 & 3 & 4.8 & 200 & $\begin{array}{c}1.0 / 1.5 / \\
1.0 / 1.4\end{array}$ \\
\hline 7 & $\begin{array}{c}20.2 / 22 . \\
5 / 25.0 / 2 \\
2.3\end{array}$ & 40.0 & 2 & 22 & 9 & 1 & 30.2 & 100 & $\begin{array}{c}7.2 / 6.7 / \\
8.0 / 8.5\end{array}$ \\
\hline 8 & $\begin{array}{c}22.4 / 22 . \\
7 / 23.1 / 2 \\
2.9\end{array}$ & 15 & 4 & 23 & 20 & 1 & & 210 & $\begin{array}{c}7.0 / 5.5 / \\
8.3 / 7.8\end{array}$ \\
\hline
\end{tabular}

Table IV

The processed data

\begin{tabular}{c|c|c|c|c|c|c|c}
\hline $\begin{array}{c}\text { The } \\
\text { candidate } \\
\text { suppliers } \\
\text { number }\end{array}$ & $\begin{array}{c}\text { Price } \\
\text { (I) }\end{array}$ & $\begin{array}{c}\text { Level of on } \\
\text { time } \\
\text { delivery } \\
\text { (I) }\end{array}$ & $\begin{array}{c}\text { The average rate } \\
\text { of customer } \\
\text { complaints } \\
(\%)\end{array}$ & $\begin{array}{c}\text { After-Sales } \\
\text { service } \\
(\mathrm{I})\end{array}$ & $\begin{array}{c}\text { The level of } \\
\text { quality } \\
(\mathrm{O})\end{array}$ & $\begin{array}{c}\text { The } \\
\text { emergency } \\
\text { supply } \\
\text { ability } \\
(\mathrm{O})\end{array}$ & $\begin{array}{c}\text { Supply } \\
\text { history }\end{array}$ \\
\hline 1 & 21.56 & 3.0 & 6 & 12 & 40.3 & 590 & 41.5 \\
\hline 2 & 21.43 & 30.0 & 20 & 196 & 30.0 & 260 & 30.3 \\
\hline 3 & 23.31 & 21.0 & 16 & 50 & 31.0 & 290 & 31.2 \\
\hline 4 & 20.25 & 6.0 & 2 & 8 & 25.0 & 550 & 25.10 \\
\hline 5 & 22.07 & 7.0 & 5 & 19 & 30.0 & 400 & 31.0 \\
\hline 6 & 21.34 & 48.0 & 10 & 51 & 4.8 & 200 & 4.9 \\
\hline 7 & 22.12 & 40.0 & 9 & 9 & 30.2 & 100 & 30.4 \\
\hline 8 & 22.79 & 15 & 17 & 20 & 28.3 & 210 & 28.6 \\
\hline
\end{tabular}

Note: In the table, (I) denotes input item, (O) denotes output item, and then using DEAP2.1 software inputs data. Calculating as follows:

Wherein Guidance Document command:

logistic.dta DATA FILE NAME

logistic. out OUTPUT FILE NAME

8 NUMBER OF FIRMS

1 NUMBER OF TIME PERIODS

3 NUMBER OF OUTPUTS

$4 \quad$ NUMBER OF INPUTS

$0 \quad 0=$ INPUT AND $1=$ OUTPUT ORIENTATED

$0 \quad 0=\mathrm{CRS}$ AND $1=\mathrm{VRS}$

0 0=DEA (MULTI-STAGE), 1=COST-DEA, 2=MALMQUIST-DEA, 3=DEA (1-STAGE), 4=DEA (2-STAGE)

b. DEA Model Results

Table V

Candidate vendor analysis

\begin{tabular}{c|c|c}
\hline \multirow{2}{*}{ The candidate suppliers number } & \multicolumn{2}{|c}{$\mathrm{C}^{2} \mathrm{R}$ model } \\
\cline { 2 - 3 } & Relative efficiency & Ranking \\
\hline 1 & 1.000 & 1 \\
\hline 2 & 0.749 & 5 \\
\hline 3 & 0.711 & 6 \\
\hline 4 & 1.000 & 1 \\
\hline 5 & 0.813 & 4 \\
\hline 6 & 0.342 & 8 \\
\hline 7 & 0.999 & 3 \\
\hline 8 & 0.664 & 7 \\
\hline
\end{tabular}

c. Analysis Calculation Results

As we can see from Table V, supplier 1 and supplier 4'efficiency is 1 in $C^{2} R$ model, indicating that both enterprise scale and technique are effective, and its efficient frontier is formed constant 
returns of scale, which is a species ideal state that is good allocation resources, not wasteful, appropriate input and output, and it should be based on this keeping continue.

At this time, two suppliers' relative efficiency is 1 , and it should be the next step, using ANP method to evaluate the two vendors supply chain.

\section{B. Evaluate Supply Chain}

\section{a. Original Data}

1. Supplier 1's rate of qualified product is $97 \%$, and annual sales income is 20 million yuan in which the total annual profit is 380 million yuan, and the total cost is 16.2 million, and total assets is 56.5 million yuan. The supplier has a large size and has produced more products, and this supplier adding much new services and products for the special needs of customers. Its kinds of products in 2008 is increasing from 9 to 13 , the rate of on time delivery is $92.5 \%$, and the rate of order completion is $99.5 \%$. Merging profit statement of supply companies and offsetting the internal transaction can obtain supplier 1's profit growth throughout the supply chain. According to the data can gain profit growth in the current year is PRA2008 $=25 \%$.

2. Supplier 4's rate of qualified product is $94 \%$, and annual sales income is 96.3 million yuan in which the total annual profit is 13.2 million yuan, and the total cost is 8310 yuan, and total assets is $168,356,700$ yuan. In 2008,this supplier' products kinds from six series of eight kinds increase to seven series of 10 kinds, develops new markets to meet customers' need. Due to fierce market competition, supplier 2 has greatly improved in responsiveness and punctuality, and the rate of on time delivery is $97 \%$, and order fulfilment rate is $100 \%$.With the growing competition, the slowing production and sales grow, the prices continue to decline, and the growing original material prices and other factors, the industry profit growth is decline, but the goal of supply chain with its improving sales service, quality management makes profit growth and its' profit growth rate is $30 \%$. b. Supply Chain Evaluation Data Processing

1. Index System: This case uses analytic network power (ANP) process to evaluate suppliers in the supply chain after the primary election, the following steps is calculating according to the ANP.

1) Control layer elements: By analyzing the control layer of quality, cost, responsiveness, financial situation, business conditions, business cooperation compatibility, communicate ability and the business environment, its correlation between these enterprises is not large, so we can conclude that they are mutually independent.

2) Network layer elements: the rate of qualified products $\mathrm{C} 1$ and quality system $\mathrm{C} 2$ of elemental focus quality with product price $\mathrm{C} 3$ and the rate of cost efficiency $\mathrm{C} 4$ of elemental focus cost are influenced each other, using double arrow express. Responsive element set has influenced on the cost element set, using a single arrow express (the more responsiveness sensitive, the response cost often rises), and product flexible C5 and emergency C6 of responsive element set's internal elements is influenced each other. The rate of capital turnover C7 and the rate of profit growth $\mathrm{C} 8$ of pecuniary condition element set is influenced each other, and it is independent element. The rate of on time delivery $\mathrm{C} 9$ and the rate of order completion $\mathrm{C} 10$ of business condition set is influenced each other (the higher on time delivery rate, the higher order completion rate).The strategic target consistency $\mathrm{C} 11$ of enterprise cooperation compatibility concentrated has influenced on information platform compatibility $\mathrm{C} 12$, so it is independent with each other. Communication degree $\mathrm{C} 13$ of communication ability set and information level C14 is influenced each other, the high information level is good for communication, and information level is also affect the information platform compatibility. Two factors of business environment set is influenced each other, but the correlation is not very big. In order to objectively evaluate the supply chain, this paper is assumed that they are independent with each other.

According to M company's supplier requirements, it has established supplier evaluation system shown in Fig 1, 


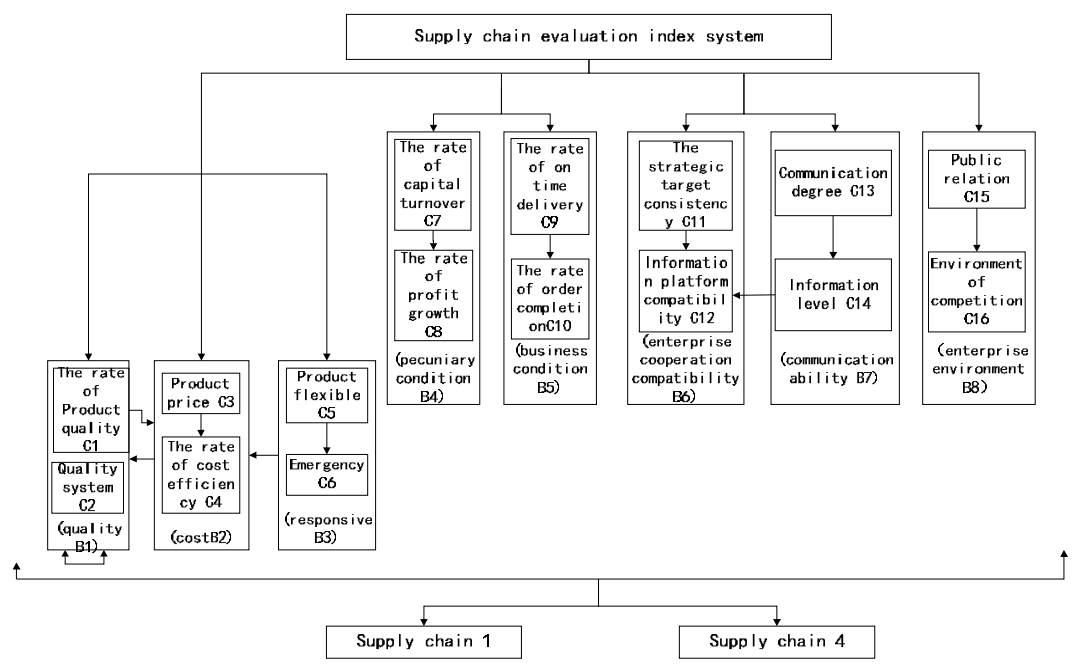

Fig.1 Supplier evaluation system

2. Establish Supply Chain Evaluation Model: Model has been established in accordance with the order which is first the control layer and then the sub-rule layer, according to the forth large sections' model ideas in turn set up, and then according to Fig.1 and Table I dependency relationship between the factors of determining the relationship between element set. This paper use SD (super decisions) software model and calculation. The model is that correlation between the modules of the model and the elements between the modules also are interconnected.

By determining the weight of index factors and determining the weights of various factors in the evaluation index system of supply chain (detailed steps can be reference for the implementation of the analytic hierarchy process (AHP) to determine the weight, not repeat them here), then by the model which is depended on elements make the index weight of the primary and secondary factors in accordance with the SD software prompts inputting step by step, and then it can be obtained the unweighted super matrix, the weighted matrix, and the limit super matrix.

$W_{i j}$ of unweighted super matrix table shows the effect degree of $\mathrm{i}$ element to $\mathrm{j}$ element, for example, $W_{56}=0.75$ indicating the response degree of flexibility product C5 affecting emergency C6 is 0.75 .

Weighted matrix has different meaning from unweighted super matrix which represents the interaction degree between the elements of the systems and also is the result of the main factor and the secondary factors, such as $W_{56}=0.1875$, and its value is different from the unweighted super matrix.

Limit super matrix table is the final output shown in Fig.2. The weight of each sub-criterion layer can be calculated corresponding results, such as the C2 quality system weight is 0.1341 .

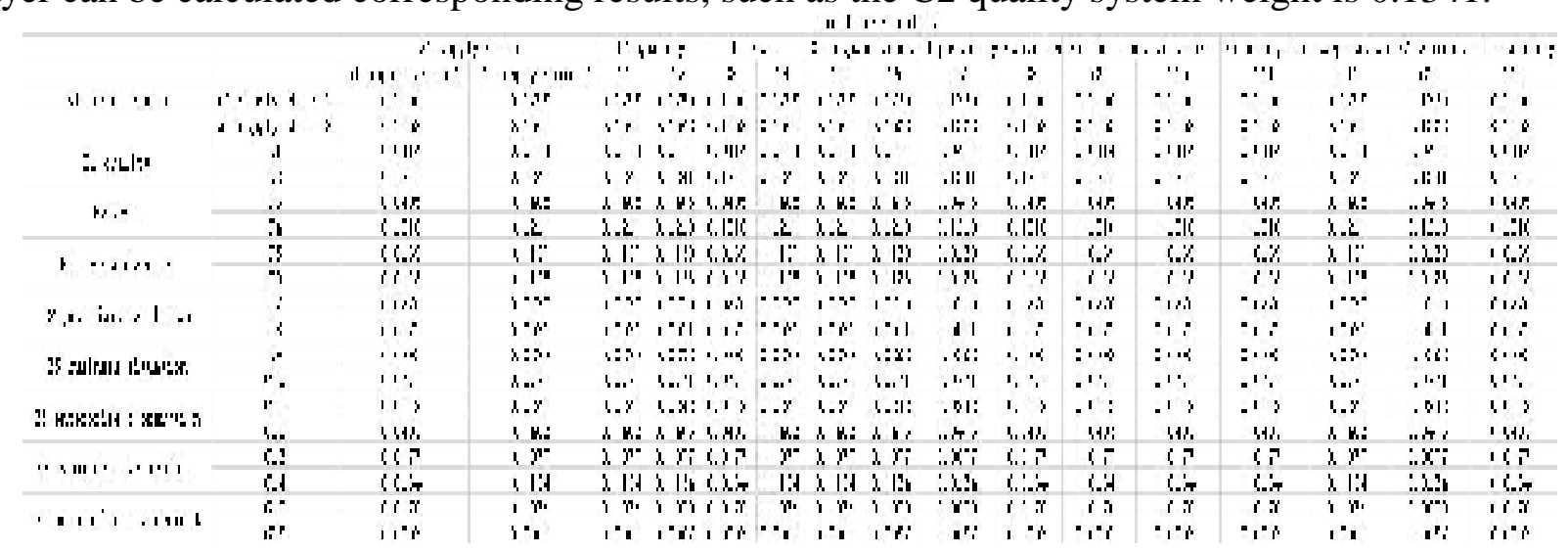

Fig.2 Limit super matrix

\section{c. Result Analysis}

Seen from the limit super matrix, supply chain 1 and supply chain 4's weight index respective is: $0.1796,0.1562$, and its normalized results is: $0.5348,0.4652$. As can be seen from the data supply 
chain, supply chain 1 is superior to supply chain 4 , so companies should choose superior 1 as the best provider, and also be used as a long-term close strategic partner.

\section{Conclusion}

This paper were researched the supply chain partners of small and medium-sized manufacturing enterprises. Selecting Suppliers is a multi-criteria problem that is combine qualitative factors with quantitative factors. On the basis of research status, this article creative combines the data envelopment analysis DEA with network analysis methods ANP. First using the DEA method established the efficiency evaluation model and index system of suppliers, and then using the ANP method established the evaluation model and index system of supply chain on which vendors located. DEA method is a quantitative method, and it can research the rationality of the supplier's resource allocation, make the primary election to the suppliers, and overcome the subjectivity of the AHP and other methods determining the index weight. Indicators are affected by each other between ANP method which is overcoming the shortcomings of AHP index that it only has the vertical hierarchical mutually independent. Combination of both methods is a combination of qualitative and quantitative, and breaking the status quo of the traditional supplier selection and supply chain evaluation phase separation. Using horizontal and vertical cross-evaluation is a new method of program evaluation.

\section{Acknowledgment}

This work was supported by funding project for Youth Talent Cultivation Plan of Beijing City University Under the grant number (CIT\&TCD201504051), supported by Beijing WUZI University Cultivation Fund Project (GJB20143006), supported by Beijing Key Laboratory(NO:BZ0211) and Beijing Intelligent Logistics System Collaborative Innovation Center.

\section{References}

[1] Jafar Rezaei. A two-way approach to supply chain partner selection [J].International Journal of Production Research, 2015, 53(16):4888-4902.

[2] Chong Wu,David Barnes. Partner selection in agile supply chains: a fuzzy intelligent approach [J]. Production Planning and Control, 2014, 25(10):821-839.

[3] Dubow, Mark. Evaluate business plans, select strategic partners by taking a 10-step approach [J]. Health Care Strategic Management, 2006, 24(10):1-16.

[4] Zhang Feng, Song Xiaona, Yin Xiuqing. Based on AHP and TOPSIS method of evaluation and selection of supply chain partners [J].Industrial economic BBS, 2015, (2):95-104.

[5] Guo Siqi. Analyses how to evaluate supply chain partners [J].Brand, 2015, (10):95.

[6] Qiu Zengjian. The improved AHP method in the analysis of application of international project risk assessment [J].Jiangsu building materials, 2016, (1):57-60. 